\title{
Aventais (não mais) sujos de ovos: re(a)presentaçóes
}

\author{
Tânia Regina Oliveira1Ramos* \\ Universidade Federal de Santa Catarina
}

\begin{abstract}
Resumo: $\mathrm{O}$ título, na sua ambiguidade, vem de uma canção em homenagem às mães: "Mamãe, mamãe. Eu te lembro chinelo na mão, avental todo sujo de ovo", O objetivo deste ensaio é mostrar narrativas contemporâneas que buscam representar pela escrita os sentidos da paixão da mulher urbana moderna, suas experiências de moralidade, o que resta do que se chamou arquetipicamente respeitabilidade e responsabilidade doméstica.
\end{abstract}

Palavras-chave: Escritoras brasileiras. Escrita feminina. Maternidade.

Mamãe, mamãe, mamãe,

Eu te lembro o chinelo na mão

$\mathrm{O}$ avental todo sujo de ovo

Se eu pudesse

Eu queria, outra vez, mamáe,

Começar tudo, tudo de novo.

Rainha do lar, David Nasser e Herivelto Martins

\footnotetext{
* Doutora em Letras pela Pontifícia Universidade Católica do Rio de Janeiro. Atualmente é professora Associada IV e coordena o núcleo Literatura e Memória da UFSC, núcleo com projetos aprovados pela FAPESC e CNPq. Faz parte da Coordenação Geral da Revista Estudos Feministas e do Conselho Editorial das revistas Anuário de Literaura, UniLetras, Mafuá, Ciências e Letras, Literatura Hoje, Signótica. É professora de Literatura Brasileira no Curso de Letras da UFSC. Atua, pesquisa e publica nas linhas de pesquisa História e Memória, escritas de si e gênero.
}

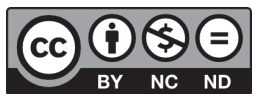

Esta obra está licenciada sob uma Licença Creative Commons. 
Duas antologias de contos organizadas por Luiz Ruffato em 2004 e 2005, intituladas, respectivamente, 25 mulheres que estão fazendo a nova literatura brasileira e +30 mulheres que estão fazendo a nova literatura brasileira, têm sido de extrema importância para indicar caminhos de pesquisa na direção de algumas das mais representativas escritoras brasileiras contemporâneas. ${ }^{2}$

A grande maioria dos 55 contos selecionados para as duas antologias presentifica o papel da mulher em situaçôes em que ela não é apenas confrontada no espaço erótico ou sexual para atender ao pressuposto masculino como padrão de referência, mas se mostra muito mais como presença de uma nova história.

Nelly Richard, em seu artigo “A escrita tem sexo?" (2002), fala da necessidade de se constituir um corpus antes de se pensar em literatura feminina, pela possibilidade de se ler ali alguns denominadores comuns dessa produção contemporânea. Na economia biográfica das autoras reunidas nas duas antologias, constato que essas mulheres que escrevem no e para o século XXI fazem parte de um universo humanístico voltado para a performance do corpo, para a linguagem, para a palavra e para a expressão artística: dez jornalistas, três funcionárias públicas, dez formadas em Letras, duas em Música, quatro publicitárias, uma pedagoga, uma psicanalista, oito professoras, uma socióloga, uma roteirista, três tradutoras, uma shiatsuterapeuta, uma arquiteta, duas editoras, uma crítica de arte, uma religiosa... ${ }^{3} \mathrm{Dez}$ se assumem escritoras e uma delas se declara "escritora profissional". ${ }^{4}$ Uma comunidade de destinos.

\footnotetext{
${ }^{2}$ Publiquei em 2010, no livro Deslocamentos de gênero na narrativa brasileira contemporânea, organizado por Regina Dalcastagné, o ensaio "Talentos e formosuras", exatamente para mostrar a importância das duas antologias de Luiz Ruffato para futuras pesquisas. Esse ensaio está no prelo para publicaçáo em 2013 pela Editora da UFG em um livro organizado pelos professores doutores Pedro Fonseca e Luciana Borges.

${ }^{3}$ Algumas acumulam funçōes profissionais como "jornalista e publicitária", "ex-musicista e tradutora".

${ }^{4}$ Letícia Wierzchowski (Porto Alegre, 1962), escritora profissional, mora em Porto Alegre. 162
} 
Como estabelecer uma relação entre preconceitos, representaçóes e linguagem, quando se busca entender alguns ruidos na representação das mulheres pelas mulheres?5 $\mathrm{O}$ eixo da reflexão é essa mulher que escreve, a escritora, em um contexto no qual a cultura parece estar ainda pouco combativa e engajada nas questóes que se referem às práticas de escrita, à função autoral. Perguntamos: a escritura e a escritora situam-se também no e para o espaço de uma literatura conceitual e crítica? Como deixar ouvir a voz das mulheres que fazem literatura, das que pensam a literatura? É preciso saber o que elas dizem como voz autoral e como personagens nas muitas narrativas disseminadas em pequenas editoras, em antologias, em abordagens críticas acadêmicas ou midiáticas.

Confere-se, em primeiro lugar, que certos procedimentos narrativos nesse corpus analisado são semelhantes, uma vez que partimos do princípio de que hoje se faz uma literatura muito mais globalizada do que interna(ciona)lizada. São escritas do cotidiano, que transformam o viver e o escrever numa mesma coisa. Nâo se encontra nos textos apenas a vivência metafísica no plano subjetivo, que marcou, por exemplo, a obra de Clarice Lispector. As personagens femininas tomam a iniciativa no jogo de sedução da escrita ou do sexo e são interessadas no seu próprio prazer, ao colocar as mulheres, ou as personagens femininas, como sujeito de uma ação narrativa mais transgressora.

Isabel Allegro de Magalhães, ao escrever uma coletânea de análises de escritoras e escritores portugueses contemporâneos, em seu livro $O$ sexo dos textos e outras leituras, nega a relação direta entre escrita feminina e categoria mulher, afirmando que se deve procurar "identificar indicadores de uma outra sensibilidade, de uma outra percepção do real, de uma outra lógica, expresssos literariamente nos textos e afins

\footnotetext{
${ }^{5}$ Este ensaio estabelece um diálogo com o texto "Gatas pingadas", apresentado no simpósio temático "Ruídos na representação da mulher", organizado pelas professoras Tânia Regina Oliveira Ramos e Regina Dalcastagné, no Seminário Internacional Fazendo Gênero 7, Florianópolis, Universidade Federal de Santa Catarina, 28 a 30 de agosto de 2006.
} 
à experiência das mulheres: à sua experiência corporal, social, cultural" (1995, p. 13).

As transgressões são levadas no interior da batalha discursiva, na qual, acima de tudo, vê-se a elaboração da linguagem como fenômeno estético, uma consciência plena da língua e da linguagem como instrumento de trabalho, uma conquista erótica da própria fala. E quem detém a fala detém o poder. Cito, para ilustrar minha afirmação, parte de uma entrevista de Márcia Denser, autora e pesquisadora de escritas eróticas, na qual ela diz:

\begin{abstract}
A conquista de uma voz própria, de uma voz pública, universal, polissêmica, plurivalente, que é manifesta ao se atingir um estilo único, meta de todo escritor, seja mulher ou homem, é algo que precisa passar antes pelo exercício, pelo domínio, pela superação, pela incorporação de um discurso erótico. Esta é minha tese e, ao que parece, não é um problema apenas da mulher latino-americana ou das mulheres do terceiro mundo, mas pós-90, é um problema colocado também para as mulheres do segundo e primeiro mundo ocidentais tendo em vista os retrocessos do feminismo [...] acrescido do fato do discurso cinematográfico hollywoodiano, no qual esta mulher está inserida, penetrar o imaginário globalmente. (DENSER, 2005, on-line)
\end{abstract}

Kerstin Behnke em seu ensaio "A crise da representação" (1994) descreve a experiência do fim de século XIX, quando os sistemas de representaçấo humana, particularmente a linguagem, considerados suficientes na época clássica, já não se mostravam adequados à realidade. $\mathrm{O}$ termo representação perdeu, enquanto forma de conhecimento, sua garantia universal. A representação veio a ser posta na lista do não mais possível da pós-modernidade.

Nesse espaço da impossibilidade, penso em algumas re(a) presentaçóes que podem se dar pelas alusóes autorreflexivas da linguagem literária na sua própria ficcionalidade e, a partir delas, entender, por exemplo, a superação do que se chamou de corpos 164 
dóceis no espaço familiar. Penso igualmente na possibilidade poética e ficcional que, alegoricamente, busca superar figuraçôes estereotipadas como a que dá título a esse ensaio e representar pela escrita outros sentidos da paixão da mulher urbana moderna, suas experiências de moralidade e responsabilidade doméstica. Por outra parte, busco pensar, principalmente, a questão familiar, como núcleo contemporaneamente re(a)presentado no qual a sexualidade e o erotismo são diluídos ou substituídos pela recorrência de sentimentos fortes - raiva e ódio, alternados com amor, humor e alegria, resultantes das experiências pessoais com o cotidiano, das reflexóes dos indivíduos sobre si mesmos ou das vivências individuais.

O ponto de partida da reflexão foram os contos "Mãe, o cacete", de Ivana Arruda Leite (2004), e "Dos amores fingidos", de Maria Ester Maciel (2005), exatamente pela capacidade desconstrutora do estereótipo do "inabalável amor filial" e do modo como economicamente nos mostram que as cenas eróticas no espaço doméstico podem ser menos gráficas e muito mais alusivas a recursos da memória, a modos de contar. O conto de Ivana Arruda Leite começa com a provocativa frase: "Mãe é uma cruz na minha vida. Nunca gostei da minha e duvido que as pessoas gostem tanto da sua quanto dizem" (LEITE, 2004, p. 213).

Vamos, então, a alguns conflitos familiares na literatura brasileira contemporânea. Narrativas de estrutura simples apresentam relatos de aparência banal - a tensão se dá no embate pai e mãe versus filhos e filhas - e encontros entre personalidades conflitantes, que, muitas vezes ignorando situaçóes particulares, surgem como representantes do maniqueísmo social que divide os indivíduos em bons e maus. Por sua vez, há narrativas marcadas por uma maior complexidade, com diversos temas entrelaçados em estruturas literárias mais elaboradas, com narradoras sofisticadas, múltiplos focos narrativos, sutilezas de linguagem, fragmentaçáo narrativa, jogos de cena, teatralizaçóes do enredo. 
Estabelecem-se nessa oscilação as particularidades que poderiam traçar uma espécie de cartografia consanguínea na literatura brasileira, ${ }^{6}$ no sentido literal ou no sentido de uma tradiçấo literária. A título de ilustraçáo remeto a um livro que, embora premiado - e talvez por isso -, não teve o merecido reconhecimento da crítica literária: As netas de Ema, de Eugênia Zerbini. Para a autora, além de alimentar a dúvida no próprio título - ema, qual ema? ema, a ave? ema, anagrama de "mãe"? -, o seu romance também quer mostrar muita intimidade com as aventuras, ilusôes, desilusôes, erros e acertos de Emma Bovary. Com bastante consciência de seu fazer literário, Eugênia Zerbini mostra em As netas da Ema que há uma geração de mulheres que, embora tenham tido possibilidade de escolha, restringiram-se sigilosa e voluntariamente aos fantasmas invocados. ${ }^{7}$

Historicamente, em situaçóes em que o pai se ausenta (física ou psicologicamente, espontaneamente ou de forma forçada), a quem compete o poder? No caso dos contos que nos servem como suporte de análise, compete às filhas a revolta contra o que foi imposto pela tradição. Para aquelas que se reconhecem incompletas (porque criadas pela onipresença materna), a revolta, expressa através da insurreição, surge como uma alternativa emocionalmente aceitável. E isso significa entender/estender que há momentos em que somente o efeito devastador é capaz de impedir a continuidade do sofrimento. $\mathrm{O}$ conflito, nesse contexto revelado pela ironia, se apresenta como instrumento libertador: "Minha mãe ficou encravada na cama muito tempo até que amanheceu morta. Finalmente eu estava órfā” (LEITE, 2004, p. 214).

Emboraanarrativanãosedetenhanasminúciasdodesentendimento - "rezei porra nenhuma. Não gosto da máe de ninguém, nem da mãe de

\footnotetext{
${ }^{6}$ Em 2009, foi defendida na Universidade Federal de Santa Catarina, sob minha orientação, a tese de doutorado $A$ invenção do inimigo, de Raul Arruda Filho, em que ele aprofunda a questão dos irmáos representados na literatura brasileira, centrando o foco de análise na representaçáo de gêmeos, principalmente nos personagens dos romances Esaú e Jacó, de Machado de Assis, Pedro e Paula, de Helder Macedo, e Dois irmãos, de Milton Hatoum.

7 Sobre esse livro de Eugênia Zerbini e $O$ vôo da guará vermelha, de Maria Valéria Rezende, escrevi o ensaio "Narrativas com fôlego", publicado em 2007, pela revista Letras de Hoje, da PUC-RS.
} 
Jesus" -, é possível perceber que mãe e filha fazem da vida familiar uma disputa incessante. Essa rixa é potencializada no tailleur da mãe, na meia de seda, no colar de pérolas, no rouge, na porta aberta, na perna aberta... $\mathrm{E}$ assim, pelos caminhos tortuosos da superação emocional, compete à filha transformar a ausência em complemento, na medida em que a filha refreia o confronto e o ódio.

Aluguei o quarto de minha mãe para um calouro de Medicina: o Rui, 20 anos, recém-chegado à capital. Os pais ficaram felizes ao saber que ele moraria em casa de senhora tão distinta. (LEITE, 2004, p. 215)

Uma situação similar encontro em "Dos amores fingidos", conto de Maria Ester Maciel que esvazia o estereótipo de candura e fragilidade na relação mãe e filhas. A disputa amorosa entre as mulheres, Odília, a mãe, e as irmãs Lídia, Catarina e Maria Alice, a filha adotada, está de tal forma carregada de indiferença que lembra conflitos arquetípicos.

Da família não recebeu mais nada, a não ser desdém e desonra. Hoje perambula pela vida, sem qualquer recompensa pelos seus atos insanos. Carrega no corpo a lembrança da mãe postiça, que, por sua vez, nenhum bem concede à filha, por mais que essa padeça ou mendigue. (MACIEL, 2005, p. 127)

Não há da parte das escritoras, ou dessas vozes autorais, apenas espaços de tensão ou o desejo de esconder os conflitos familiares, fingindo que eles não existem, instituindo um método muito particular de administrar a economia afetiva doméstica. Recupero, para falar desta economia doméstica, a metáfora do "avental não mais sujo de ovo" enquanto representaçáo da mãe, rainha do lar, a mãe que se vestia e não se despia para os ritos cotidianos e que fez parte durante tanto tempo de um imaginário coletivo: "Ela era a dona de tudo, era a rainha do lar/ Ela vale mais para mim, que o céu, a terra e o mar". Ana Gabriela Macedo e Ana Luisa Amaral, em Dicionário de crítica feminista, nos dizem que o olhar 
pós-moderno sobre a maternidade desafia as representaçóes essencialistas universalistas e que as mães devem ser trazidas para o terreno da discussão feminista (MACEDO; AMARAL, 2005, p. 125).

$\mathrm{O}$ resgate de re(a)presentações de mulheres, ou de um silêncio nunca preenchido, de vozes caladas pelo século XIX e parte do século XX e pela sempre importante pesquisa dos percursos da representação do feminino permitem a leitura de certas narrativas contemporâneas (pre)ocupadas em mostrar as filhas do sêmen (porque o Pai, enquanto corporalidade, costuma ser uma falta) como antagonistas da mãe. Como consequência imediata desse ponto de vista, a representação literária procura mostrar que os temas são focados de uma forma realista e menos aberta a qualquer idealização romântica da figura materna. As escritoras, por meio de suas narradoras e personagens, mesmo em primeira pessoa, preferem participar do espetáculo familiar, em lugar seguro, sem muito envolvimento, sem o desejo de "começar tudo, tudo de novo". Não há preocupaçâo de preservar a imagem da família (de "certas" infelicidades), nem limitar o campo de visão, mas mostrar o que está acontecendo em salas e quartos - porque lá sempre está acontecendo alguma coisa.

Mais do que um momento em que a literatura reafirma a educação sentimental que perpassa necessariamente pela sexualidade, em que as diferenças são confrontadas com o tempo pretérito, as narrativas que falam de máes e de filhas fazem de uma maneira minimalista a representação do que se pode chamar de catástrofes privadas. Sem muitos detalhes. Pequenos pormenores ou breves alusôes. Só para ilustrar cito aqui breves passagens de alguns outros contos lidos para esta análise. Em "Bondade", de Simone Campos, a falta de assunto para o conto aparece assim: "Por um bom tempo tentei escrever para falar mal de minha mãe" (CAMPOS, 2005, p. 29). Em "O sétimo mês", de Cecília Costa, a gravidez é assim representada:

E assim a barriga de Emília foi crescendo, crescendo, crescendo numa imensa solidão [...] a criança que viria e certamente seria uma mulher. A certeza era táo clara, 
claríssima, que foi este o nome escolhido para a filha. Clara, Clara de ovo, Clarissa. (COSTA, 2005, p. 66)

Em "Xadrez", de Paula Taitelbaum, a personagem Tina, que faz às vezes da mãe nas tarefas domésticas, é assim narrada: "Ela secou as mãos no avental, um gesto que sempre se repetia, mesmo que as mãos estivessem limpas e secas" (2005, p. 277).

A ação narrativa fica assim circunscrita ao registro de memórias traumáticas, visuais, de mães e filha(s) que a vida separou. Em cada silêncio ou desabafo, sem diálogo, há uma inquietação imprecisa, um hiato cheio de fragilidade, um sentimento similar à saudade, que não se deseja saudade. E isso se confirma na troca de informaçóes pouco específicas sobre a família de cada uma delas e na camaradagem que beira a angústia e o medo - embora esteja pontuada por reminiscências.

Difícil terminar este ensaio em que falo de mães e filhas sem me remeter ao livro de Heloísa Seixas, O lugar escuro, um livro autobiográfico, memorialístico, em que ela, a autora, vai ancorar a sua história no relato da doença de sua mãe, que sofre de mal de Alzheimer associado a outras formas de senilidade. ${ }^{8}$ No início de 2007 , ela resolveu contar essa história, ao mesmo tempo em que cuidava de sua mãe - que acabou se tornando um livro sobre sua própria história e de sua família.

O mais difícil foi admitir a raiva. Mas ela aconteceu quando minha mãe estava bem ainda, tinha autonomia de voo. Era uma mente totalmente destroçada num corpo são. Parecia às vezes que estava brincando comigo. Eu tinha raiva daquela pessoa em quem ela tinha se transformado. (VIANNA, 2007, p. 13)

A degeneração da mãe - cujo nome não aparece no livro, assim como o de nenhum outro personagem - fez substituir a raiva pela compaixão.

\footnotetext{
${ }^{8}$ Sobre este livro, numa análise comparativa com a narrativa de Cristóvão Tezza, $O$ filho eterno (Record, 2010), publiquei o ensaio "Narrativas-coragem", no volume 1 do livro Leituras de resistência (Mulheres, 2009).
} 
"Escrevi o livro porque achei que a história estava resolvida na minha cabeça. Mas foi importante como um arremate dessa serenidade. É um acerto de contas com final feliz", afirma ela, não vendo no seu texto nenhum apelo para que sintam pena dela. [...] "Autocomiseração é muito ruim, porque você tende a ter um apego à dor. Quando se expóe, é para se livrar dela". (VIANNA, 2007, p. 7)

Por fazer um romance sem estar subordinada à economia do conto, Heloísa Seixas narra essa história real, a sua própria história, entrelaçada com um pesadelo familiar. Todas as fases da degradação da mente comprometida pelo mal de sua mãe são descritas de forma minuciosa e atenta nesse livro que, de tão bem construído em seus mo(vi)mentos, às vezes parece ficção, ou "uma espiral assombrada", como define a escritora. Como quem procura a possibilidade de se sair com mais facilidade de um labirinto, Heloisa Seixas vai contando essa trajetória, que nos atrai, mesmo que pelo estranhamento e loucura. Ela traz para a narrativa suas raízes familiares, a descrição do casarâo da Bahia, a vida no Rio de Janeiro dos anos dourados, nessa viagem ao passado de sua mãe. Pratica o crime imperfeito (uma vez que o crime perfeito pressuporia a eliminação do real), como diria Baudrillard, a sua própria realidade entrelaçada com um pesadelo familiar.

Houve momentos, durante o processo de esfacelamento da mente de minha mãe, em que senti que me degradava também, que me desfazia, que ameaçava resvalar perigosamente para o outro lado - o lado da insanidade. Penso que essa foi uma das razóes que me levaram a escrever um livro sobre o mal de Alzheimer. Quando me sentei no computador, não sabia ao certo o que faria. Deixei que meus dez dedos, pousados sobre o teclado, decidissem tudo, caminhassem sozinhos. Escrevi durante semanas, de forma febril. E assim se fez O lugar escuro - uma história de senilidade e loucura. É um relato da minha convivência com a doença e também uma viagem ao fundo da mente de minha mãe. Uma catarse que me ajudou a entender e, principalmente, a aceitar muitas coisas. Acho que esta 
é a palavra-chave: aceitação. Não é fácil ver alguém com quem se conviveu por toda a vida se transformar em outra pessoa. ("Um acerto de contas", 2007, p. 9)

Encerro minha leitura sobre as narrativas que abordam diretamente ou de forma simbólica as relaçôes entre irmãs, filhas e mães (e por extensão, com os demais componentes do núcleo familiar). Quis mostrar que a sexualidade e o erotismo, aqui representados, em uma presença-ausência no enunciado, por corpos muitas vezes incestuosos, delineiam uma paisagem afetiva que é comum às leitoras e aos leitores. A identificação é imediata, porque, historicamente, todos os grupos sociais elaboraram um padrão de referência sobre o tema. E, na modernidade, há uma coragem para expurgar fantasmas e as relaçốes estão edificadas em uma base sedimentada por novas subjetividades. O conto "Mãe, o cacete", um breve conto que, lido na sua inteireza, permite o riso e o relaxamento mesmo diante de um tema duro, pesado, o desamor filial e materno, termina com a pergunta: "E pai... O que é um pai para você?”. Uma pergunta feita por Rui, o estudante de 20 anos, à personagem-narradora, mas muito mais a nós, leitoras e leitores: "O que é um pai para vocês?” As narrativas são povoadas de mães e filhas, com voz e com atitudes, e a figura paterna foi ficando cada vez mais apagada ou distante. Praticamente ausente. Não explorar a figura do pai nessas histórias de mulheres é um modo de re(a)presentar a falta na nova configuração familiar. Uma falta que não faz falta. Não se trata de apagar a padronização das relaçóes entre os dois sexos, homem e mulher, mãe e pai, mas ausentar das narrativas a assimetria na posição dos gêneros masculino e feminino em relaçáa às estruturas de poder. Essas narrativas contemporâneas que apagam a figura do poder paterno são também formas de resistência de continuar escrevendo as mesmas histórias calcadas nas estruturas patriarcais históricas.

Em síntese, as desavenças e os afetos que envolvem as relaçóes familiares transformam a sexualidade, o erotismo, a afetividade e o desamor em potencial literário rico em tensão dramática, histórias que articulam significativa carga emocional, situaçóes surpreendentes e desfechos inesperados, corpo e sensualidade, como as que aqui 
transcrevo, tomando de empréstimo duas significativas passagens do inconformismo das filhas diante dessa nova mulher, em dois contos escolhidos entre os 55 contos lidos para este trabalho.

Ontem um amigo do Rui veio visitá-lo. — A senhora é mãe do Rui? perguntou ao me ver.

- Mãe, o cacete - respondi atordoada. Sou a mulher que dorme com ele, que faz a comida dele, que cuida da roupa dele, da casa dele.

- Praticamente uma mãe - o cínico completou.

Deus me livre ser mãe do Rui. Mãe é uma desgraça na vida de qualquer pessoa. Mãe não deixa a gente ser feliz. (LEITE, 2004, p. 208)

Casou-se aos quinze anos, ficou viúva aos trinta e teve duas filhas: Lídia e Catarina. Às duas deu o que tinha e o que não tinha, com uma volúpia indecisa. Da segunda, sugou todos os afetos até a medula. E da primeira cobrava tudo com juros e espinhos. Cobrou, inclusive, o leite que a menina consumira de seus peitos agora ressequidos. E assim mesmo ainda se indigna com a frase que, numa tarde insípida, Lídia lhe lançou, em estado de vertigem: me livra de ter nascido de ti, mesmo que por um dia. (MACIEL, 2005, p. 125)

\section{Referências}

BAUDRILLARD, Jean. O crime perfeito. São Paulo: Relógio D’Água, 1996.

BEHNKE, Kerstin. Crise da representação. Cadernos do Mestrado/ Literatura, Universidade do Estado do Rio de Janeiro, Rio de Janeiro, n. 10, p. 15-27, 1994.

CAMPOS, Simone. Bondade. In: RUFFATO, Luiz (org.). + 30 mulheres que estão fazendo a nova literatura brasileira. São Paulo: Record, 2005, p. 27-51.

COSTA, Cecília. O sétimo mês. In: RUFFATO, Luiz (org.). + 30 mulheres que estáo fazendo a nova literatura brasileira. São Paulo: Record, 2005, p. 89-123. 
DENSER, Márcia. Entrevista da escritora e filósofa Márcia Denser. In: VERDES TRIGOS, 3 dez. 2005. (On-line). Disponível em: http:// www.verdestrigos.org/sitenovo/site/cronica_ver.asp?id=824. Acesso em: 21 jan. 2012.

LEITE, Ivana Arruda. Mãe, o cacete. In: RUFFATO, Luiz (org.). 25 mulheres que estão fazendo a nova literatura brasileira. Sáo Paulo: Record, 2004.

MACEDO, Ana Gabriela; AMARAL. Ana Luisa. Dicionário de critica feminista. Porto: Alumbramento, 2005.

MACIEL, Maria Esther. Dos amores fingidos. In: RUFFATO, Luiz (org.). + 30 mulheres que estão fazendo a nova literatura brasileira. São Paulo: Record, 2005.

MAGALHÁES, Isabel Allegro de. O sexo dos textos e outras leituras. Lisboa: Caminho, 1995.

RAMOS, Tânia Regina Oliveira. Narrativas com fôlego. Letras de Hoje, Porto Alegre, n. 150, p. 32-41, 2007.

. Narrativas-coragem. In: LAGO, Mara et al. Leituras de resistência. Florianópolis: Mulheres, v. 1, p. 127-136, 2008. . Talentos e formosuras. In: DALCASTAGNÉ, Regina; LEAL, Virginia Maria Vasconcelos. Deslocamentos de gênero na narrativa brasileira contemporânea. Rio de Janeiro: Horizonte, 2010. p. 32-49.

RICHARD, Nelly. A escrita tem sexo? In: . Intervençôes críticas: arte, cultura, gênero e política. Belo Horizonte: Editora UFMG, 2002, p. 127-141.

RUFFATO Luiz (org.). 25 mulheres que estão fazendo a nova literatura brasileira. São Paulo: Record, 2004. . +30 mulheres que estáo fazendo a nova literatura brasileira. São Paulo: Record, 2005.

SEIXAS, Heloísa. O lugar escuro. Rio de Janeiro: Rocco, 2007. 
TAITELBAUM, Paula. Xadrez. In: RUFFATO, Luiz (org.). + 30 mulheres que estão fazendo a nova literatura brasileira. São Paulo: Record, 2005.

UM ACERTO de contas. Claudia, São Paulo, 4 dez. 2007. Disponível em: http://origin.claudia.abril.com.br/materia/um-acerto-de-contas2572 ? $\mathrm{p}=\% 2 \mathrm{Fcomportamento} \% 2 \mathrm{Fsociedade} \& \mathrm{pw}=1$. Acesso em: 26 jan. 2013.

VIANNA, Luiz Fernando. Escritora Heloisa Seixas se expóe em relato da doença da máe. Folha de S. Paulo, São Paulo, 19 out. 2007. Disponível em: http://www1.folha.uol.com.br/folha/ilustrada/ ult90u337968.shtml. Acesso em: 26 jan. 2013.

ZERBINI, Eugênia. As netas da Ema. Rio de Janeiro: Record, 2005.

[Texto recebido em março de 2013 para compor a corrente edição especial]

\section{Apron (no more) dirty egg: (re)presentations}

Abstract: The title, in its ambiguity, comes from a song in tribute to mothers, "Mommy, Mommy. I remember slipper in hand, all of the apron dirty egg," The purpose of this essay is to show contemporary narratives that seek to represent by the writting the sense of passion of the modern urban woman, her experiences of morality, what is left of what was called archetypally respectability and domestic responsibility.

Keywords: Brazilian writers. Feminine writing. Motherhood.

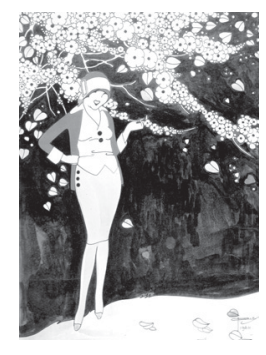

